\title{
Determination of the genetic diversity among accessions of Senna spectabilis (canafístula) by using RAPD markers
}

\author{
M.F. Santos ${ }^{1}$, R.B. Araújo Neto ${ }^{2}$, M.P.S.B.C. Nascimento ${ }^{2}$ and P.S.C. Lima ${ }^{2}$ \\ ${ }^{1}$ Genética e Melhoramento, Universidade Federal do Piauí, Teresina, PI, Brasil \\ ${ }^{2}$ Pesquisador Embrapa Meio-Norte, Teresina, PI, Brasil \\ Corresponding author: P.S.C. Lima \\ E-mail: paulo.costa-lima@embrapa.br
}

Genet. Mol. Res. 12 (4): 6149-6155 (2013)

Received May 27, 2013

Accepted October 30, 2013

Published December 2, 2013

DOI http://dx.doi.org/10.4238/2013.December.2.12

\begin{abstract}
Senna spectabilis (DC.) H.S. Irwin \& Barneby (Fabaceae; Caesalpinioideae), commonly known as "canafístula" or "cassia", is widely used in the semi-arid region of northeastern Brazil as a source of forage and timber. The plant presents a high nutritional content in comparison with other forage species that are native to the Brazilian Caatinga; thus, it represents a valuable resource during periods of drought. The aim of this study was to evaluate the genetic variability among eight accessions of $S$. spectabilis available in the forage germplasm collection of Embrapa Meio-Norte using the randomamplified polymorphic DNA technique. The 15 primers selected for use in the analysis produced 107 bands, including 59 (55.14\%) that were polymorphic. A similarity matrix was generated on the basis of Jaccard coefficients, and a dendrogram was constructed using the unweighted pair group method with arithmetic mean clustering technique. The mean value of the similarity coefficients was 0.73 , and the cophenetic correlation coefficient was $83.76 \%$. Accessions CAN. 4 and CAN. 5 presented the greatest genetic similarity, while CAN. 6 and CAN. 8 were the most divergent. The S. spectabilis accessions were classified
\end{abstract}


into two main groups with group I including accessions CAN. 1, CAN. 2, CAN. 4, CAN. 5, CAN. 7, CAN. 8, and CAN. 9, and group II comprising the single accession CAN. 6. The results presented herein revealed that, although the germplasm collection is presently limited, there is sufficient genetic variability among the accessions to permit future breeding programs.

Key words: Germplasm bank; Forage legume; Brazilian Caatinga

\section{INTRODUCTION}

The leguminous shrub Senna spectabilis (DC.) H.S. Irwin \& Barneby (Fabaceae; Caesalpinioideae) is commonly used in the semi-arid region of northeastern Brazil, where it is known as "canafístula" or "cassia", as fodder for sheep and goats; it is also used as a source of fuel wood and timber. According to Almeida et al. (2011), the protein, mineral, and fat content of S. spectabilis is high in comparison with other forage species that are native to the Brazilian Caatinga. For this reason, the plant represents a valuable nutritional resource during periods of drought. Adoption of this species as a crop and the effective use of forage conservation are practices that could be applied with substantial effects on animal farming in semi-arid regions.

In this context, active germplasm banks can play a significant role in the conservation of genetic resources. The evaluation of the genetic diversity of accessions within a germplasm collection not only provides information regarding potential genitors to be used in plant breeding but also facilitates the identification of replicates and the exchange of germplasm between researchers. Moreover, according to Borokini et al. (2010), germplasm collection represents a means of coordinating efforts directed toward the conservation of agrobiodiversity and sustainable development.

Molecular markers are valuable tools for the characterization of genetic material because they provide information about the variability of DNA between populations while eliminating potential environmental effects (Chiorato et al., 2007; Isshiki et al., 2008). Among the various methods based on polymerase chain reaction (PCR), the random-amplified polymorphic DNA (RAPD) technique is a relatively low-cost technique that is becoming increasingly popular in the genetic analysis of native and breeding populations and accessions within germplasm banks (Welsh and McClelland, 1990). The key advantage of the RAPD technique is that no previous knowledge of the genome sequence is required because the primers that are used are short synthetic oligonucleotides of random sequences that are used to amplify a set of randomly distributed loci in the genome under analysis (Caixeta et al., 2003). The objective of this study was to evaluate the genetic diversity among accessions of S. spectabilis in the forage germplasm bank at Embrapa Meio-Norte using RAPD markers.

\section{MATERIAL AND METHODS}

\section{Plant material}

Eight accessions of $S$. spectabilis were available in the germplasm collection of Embrapa Meio-Norte under the codes CAN. 1, CAN. 2, CAN. 4, CAN. 5, CAN. 6, CAN. 7, CAN. 
8, and CAN. 9. Young healthy leaves were collected separately from each accession and immediately wrapped in paper towels, placed in plastic bags, and transported to the Laboratory of Molecular Biologia at Embrapa Meio-Norte in a box filled with ice. Leaf material was stored in the freezer until required for DNA extraction in order to inhibit possible enzymatic degradation.

\section{DNA extraction}

DNA extraction was carried out with the aid of DNeasy ${ }^{\circledR}$ Plant Mini Kits (Qiagen, Valencia, CA, USA) using the method recommended by the manufacturer (Qiagen, 2006). Leaf samples $(100 \mathrm{mg})$ were transferred to $2-\mathrm{mL}$ tubes with five 3 -mm glass beads and buffers from the appropriate extraction kit and macerated in a Precellys ${ }^{\circledR} 24$ tissue homogenizer and grinder (Bertin, Montigny-le-Bretonneux, France). The quality of the extracted DNA present in $2 \mu \mathrm{L}$-aliquot samples was determined spectrophotometrically with the aid of a Nanodrop (Wilmington, DE, USA) model 2000 spectrophotometer. DNA extracts were subjected to electrophoresis on $0.8 \%$ agarose gels in Tris-borate-ethylenediaminetetraacetic acid (EDTA) (0.5X TBE) buffer, stained with SYBR ${ }^{\circledR}$ Safe DNA Gel Stain (10,000X; Invitrogen, Carlsbad, CA, USA) and quantified by comparison with $\lambda$ DNA standard (150 ng). Samples of genomic DNA were diluted in Tris-EDTA (TE) buffer to a final concentration of $15 \mathrm{ng} / \mu \mathrm{L}$ and stored in the freezer at $-20^{\circ} \mathrm{C}$ until required for PCR.

\section{RAPD reactions}

In order to select the most appropriate primers for RAPD analysis, representative samples of DNA from $S$. spectabilis accessions were amplified using 100 primers from the A, $\mathrm{B}, \mathrm{K}, \mathrm{M}, \mathrm{N}$, and P series developed by Operon Technologies (Alameda, CA, USA). Fifteen primers (Table 1) were chosen on the basis of high levels of polymorphism and good band resolution, and they were employed in the subsequent amplification of DNA from each of the eight $S$. spectabilis accessions. PCR was performed in a Veriti 96 Well Thermal Cycler (Applied Biosystems, Foster City, CA, USA) according to a modified version of the protocol of Williams et al. (1990). The reaction mixture contained $2.0 \mu \mathrm{L} 1 \mathrm{X}$ Invitrogen buffer [20 $\mathrm{mM}$ Tris- $\mathrm{HCl}, 0.1 \mathrm{mM}$ EDTA, $1 \mathrm{mM}$ dithiothreitol, 50\% glycerol (v/v), $\mathrm{pH} 8.0], 15 \mathrm{ng}$ DNA template, $3.0 \mathrm{mM} \mathrm{MgCl}, 0.25 \mathrm{mM}$ dNTPs, $1 \mathrm{U}$ Taq DNA Polymerase (Invitrogen), $0.2 \mu \mathrm{M}$ primer, and ultrapure distilled water to a final volume of $20 \mu \mathrm{L}$. The reaction conditions were: initial denaturation step at $92^{\circ} \mathrm{C}$ for $1 \mathrm{~min} ; 45$ cycles comprising denaturation at $92^{\circ} \mathrm{C}$ for 1 min, annealing at $35^{\circ} \mathrm{C}$ for $1 \mathrm{~min}$, and extension at $72^{\circ} \mathrm{C}$ for $2 \mathrm{~min}$; and a final extension step at $72^{\circ} \mathrm{C}$ for $5 \mathrm{~min}$. Amplicons were separated by electrophoresis on $1.5 \%$ agarose gels in $0.5 \mathrm{X}$ TBE, stained with SYBR Safe DNA Gel Stain $(10,000 \mathrm{X})$, visualized under an ultraviolet transilluminator, and photographed. Invitrogen 100-bp DNA ladders were used as molecular weight markers.

\section{Data analysis}

Each band on the gel was considered to represent a single marker and was ascribed the value 0 or 1 to indicate absence or presence, respectively. Genetic similarities between ac- 
cessions were estimated on the basis of the Jaccard coefficients, and a similarity matrix was constructed. A dendrogram was constructed using the unweighted pair group method with arithmetic average (UPGMA) clustering technique, and the cophenetic correlation coefficient (r) was calculated. The reliability and goodness of fit of the dendrogram was verified by bootstrap analysis based on 1000 permutations. The cut-off point was derived from the estimated mean genetic similarity $\left(g s_{m}\right)$, which was calculated from the expression $g s_{m}=\sum g s_{i j} / N$, in which $g s_{i j}$ represents the genetic similarity between each pair of individuals, and $N$ represents the number of pairs. Analyses were performed with the aid of the PAST version 1.34 software (Hammer et al., 2001).

\section{RESULTS AND DISCUSSION}

A detailed investigation of genetic diversity in manioc (Manihot esculenta Crantz) by Colombo et al. (1998) revealed that 10 to 30 RAPD primers generating 50 to 100 polymorphic bands should be sufficient to establish intra- and inter-specific genetic relationships. Of the 100 RAPD primers that were initially analyzed in this study, 15 showed a high degree of polymorphism and were chosen for the amplification reactions that were performed on $S$. spectabilis accessions. The selected primers generated a total of 107 bands (a mean of 7 bands per primer), including $59(55.14 \%)$ that were polymorphic with the potential to afford consistent information regarding the genetic distance between accessions (Table 1). The production of polymorphic bands per primer ranged between 1 and 8, with primers OP-A07, OP-A12, OP-M04, OP-M05, OP-M07, and OP-M15 generating the largest numbers of polymorphic loci. It is interesting to note that the mean number of bands per primer that was obtained in this study was higher than the reported mean of 6.8 (Nagaich and Chandra, 2009) for the important forage legume Stylosanthes hamata (Fabaceae; Faboideae) and the mean of 5.2 that was recorded by Hamza et al. (2009) for 27 accessions of the medicinal plant Cassia senna (Fabaceae; Caesalpinioideae).

Table 1. Primers employed in the random-amplified polymorphic DNA reactions of Senna spectabilis accessions.

\begin{tabular}{llcr}
\hline Primer & Nucleotide sequence & Number of bands & Number of polymorphic loci \\
\hline OP-A07 & 5'-GTAACCAGCC-3' & 8 & 8 \\
OP-A12 & 5'-TCGGCGATAG-3' & 8 & 6 \\
OP-B04 & 5'-GGACTAGAGT-3' & 5 & 3 \\
OP-M02 & 5'-ACAACGCCTC-3' & 14 & 2 \\
OP-M04 & 5'-GGCGGTTGTC-3' & 11 & 8 \\
OP-M05 & 5'-GGGAACGTGT-3' & 8 & 5 \\
OP-M07 & 5'-CCGTGACTCA-3' & 3 & 5 \\
OP-M09 & 5'-GTCTTGCGGA-3' & 8 & 1 \\
OP-M15 & 5'-GACCTACCAC-3' & 6 & 6 \\
OP-M16 & 5'-GTAACCAGCC-3' & 5 & 2 \\
OP-M19 & 5'-CCTTCAGGCA-3' & 5 & 3 \\
OP-N06 & 5'-GAGACGCACA-3' & 8 & 2 \\
OP-N10 & 5'-ACAACTGGGG-3' & 5 \\
OP-N12 & 5'-CACAGACACC-3' & 107 & 2 \\
OP-N14 & 5'-TCGTGCGGGT-3' & 5 \\
Total & & 59 \\
\hline
\end{tabular}

Analysis of the electrophoretic profiles of the bands generated by primers OP-M04 and OP-M05 (Figure 1) permitted the discrimination of all eight accessions of S. spectabilis, thus demonstrating the high efficiency of the RAPD technique in detecting polymorphism 
within this species. The Jaccard similarity matrix (Table 2) revealed that the coefficients of genetic similarity between pairs of accessions ranged between 0.61 and 0.83 , with pair CAN. 6 and CAN. 8 being the most divergent and pair CAN. 4 and CAN. 5 presenting the greatest similarity. The mean value of the similarity coefficients was 0.73 , and the coefficients of $53.57 \%$ of the pairs of accessions were below the average.

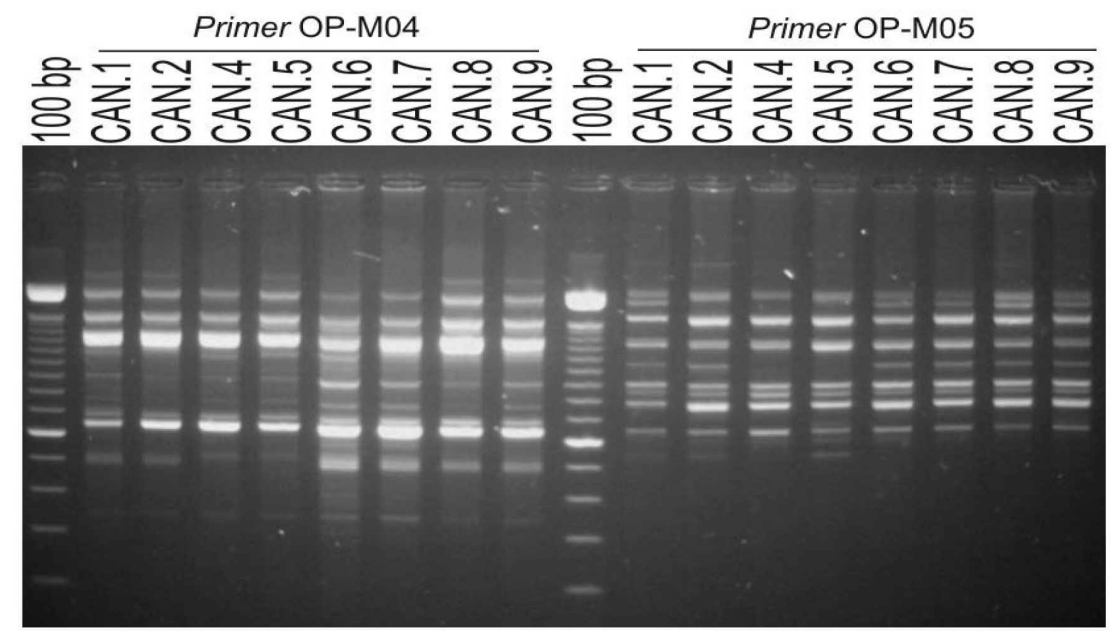

Figure 1. Amplification profiles of the eight Senna spectabilis accessions of the forage germplasm bank of Embrapa Meio-Norte obtained using primers OP-M04 and OP-M05.

Table 2. Jaccard similarity coefficients for the eight Senna spectabilis accessions of the forage germplasm bank of Embrapa Meio-Norte, as determined by RAPD analysis with 59 polymorphic markers.

\begin{tabular}{|c|c|c|c|c|c|c|c|c|}
\hline & CAN. 1 & CAN. 2 & CAN. 4 & CAN. 5 & CAN. 6 & CAN. 7 & CAN. 8 & CAN. 9 \\
\hline CAN. 1 & - & - & - & - & - & - & - & - \\
\hline CAN. 2 & 0.71 & - & - & - & - & - & - & - \\
\hline CAN. 4 & 0.78 & 0.77 & - & - & - & - & - & - \\
\hline CAN. 5 & 0.71 & 0.76 & 0.83 & - & - & - & - & - \\
\hline CAN. 6 & 0.65 & 0.68 & 0.74 & 0.66 & - & - & - & - \\
\hline CAN. 7 & 0.71 & 0.72 & 0.77 & 0.74 & 0.73 & - & - & - \\
\hline CAN. 8 & 0.72 & 0.73 & 0.73 & 0.67 & 0.61 & 0.74 & - & - \\
\hline CAN. 9 & 0.71 & 0.7 & 0.76 & 0.79 & 0.67 & 0.77 & 0.74 & - \\
\hline
\end{tabular}

Even though few genotypes were evaluated in this study, the similarity coefficients demonstrated the large divergence between the accessions. Such substantial genetic variability implies that this population could be employed in plant improvement programs.

The UPGMA dendrogram (Figure 2) that was obtained from the similarity matrix provides a graphical representation of the genetic distances among the eight $S$. spectabilis accessions. Based on the mean genetic similarity of $73 \%$, the accessions could be separated into two main clusters. Group I included accessions CAN. 1, CAN. 2, CAN. 4, CAN. 5, CAN. 7, CAN. 8, and CAN. 9, while group II comprised the single accession CAN. 6. The reliability of the data and the consistency of the nodes were verified by the bootstrap values presented in Figure 2, while the cophenetic correlation coefficient was $83.76 \%$. 


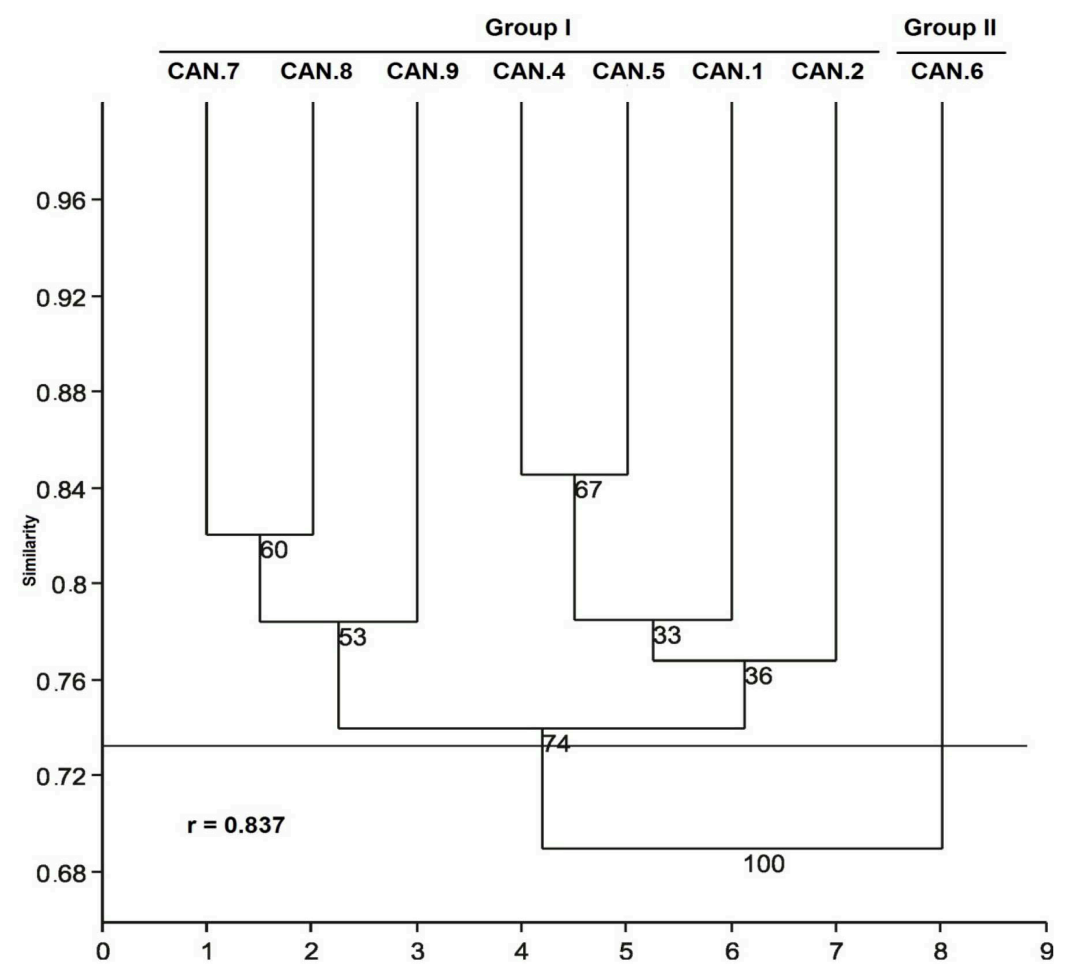

Figure 2. Unweighted pair group method with arithmetic mean dendrogram constructed on the basis of 15 random-amplified polymorphic DNA markers showing similarity relationships between the eight Senna spectabilis accessions of the forage germplasm bank of Embrapa Meio-Norte.

The results presented herein reveal that genetic variability is present in the accessions of $S$. spectabilis that are available in the germplasm collection of Embrapa Meio-Norte, but the genetic variability in these accessions is somewhat low. The reported occurrence of enantiostyly in the hermaphrodite flowers of plants of Senna (Laporta, 2005) and of $42.8 \%$ cross-breeding does not imply the elimination of self-fertilization in the genus. As observed by Laporta (2005), it is likely that the decreased variability that is detected among the accessions of $S$. spectabilis arises from self-compatibility in this species. Although the genetic variability that was detected in accessions of $S$. spectabilis in the forage germplasm bank of Embrapa Meio-Norte can be exploited in future breeding programs, it is important that the variability be expanded by collecting specimens of $S$. spectabilis from different regions because this species is widely distributed in the semi-arid areas of Brazil.

\section{REFERENCES}

Almeida ACS, Ferreira RLC, Santos MVF, Lira MA, et al. (2011). Mineral composition of arboreal and bush species occurring in pastures in Pernambuco, Brazil. Arch. Zootec. 60: 553-561.

Borokini TI, Okere AU, Giwa AO, Daramola BO, et al. (2010). Biodiversity and conservation of plant genetic resources in Field Genebank of the National Centre for Genetic Resources and Biotechnology, Ibadan, Nigeria. Int. J. Biodivers. Conserv. 2: $37-50$ 
Caixeta RP, Carvalho D, Rosado SCS and Trugilho PF (2003). Genetic variations in Eucalyptus spp. genotypes detected by means of molecular markers. Rev. Árvore 27: 357-363.

Chiorato AF, Carbonell SAM, Benchimol LL, Chiavegato MB, et al. (2007). Genetic diversity in common bean accessions evaluated by means of morpho-agronomical and RAPD data. Sci. Agric. 64: 256-262.

Colombo C, Second G, Valle TL and Charrier A (1998). Genetic diversity characterization of cassava cultivars (Manihot esculenta Crantz). I. RAPD markers. Genet. Mol. Biol. 21: 105-113.

Hammer Ø, Harper DAT and Ryan PD (2001). PAST: paleontological statistics software package for education and data analysis. Paleontol. Electron. 4: 1-9.

Hamza NB, Habeballa RS and Abdalla IE (2009). Phylogenetic relationships within indigenous Sudanese Cassia senna (L.) using RAPD molecular markers. Afr. J. Biotechnol. 8: 4824-4829.

Isshiki S, Iwata N and Khan MR (2008). ISSR variationsin eggplant (Solanum melongena L.) and related Solanum species. Sci. Hortic. 117: 186-190.

Laporta C (2005). Floral biology and reproductive system of enantiostylous Senna corymbosa (Caesalpiniaceae). Rev. Biol. Trop. 53: 49-61.

Nagaich D and Chandra A (2009). Assessment of genetic diversity and identification of informative molecular markers for germplasm characterization in Caribbean stylo (Stylosanthes hamata). J. Plant Biochem. Biot. 18: 257-260.

Qiagen (2006). DNeasy ${ }^{\circledR}$ Plant Handbook. DNeasy Mini Kit for Miniprep Purification of Total Cellular DNA from Plant Cells and Tissues, or Fungi. Available at [http://www.qiagen.com/HB/DNeasy96Plant]. Accessed October 5, 2012.

Welsh J and McClelland M (1990). Fingerprinting genomes using PCR with arbitrary primers. Nucleic Acids Res. 18: 7213-7218.

Williams JG, Kubelik AR, Livak KJ, Rafalski JA, et al. (1990). DNA polymorphisms amplified by arbitrary primers are useful as genetic markers. Nucleic Acids Res. 18: 6531-6535. 